\title{
DIREITO À SOCIABILIDADE INFANTO-JUVENIL: DEBATE SOBRE A IMPLEMENTAÇÃO DO HOMESCHOOLING
}

\section{RIGHT TO CHILDREN AND YOUTH SOCIABILITY: DEBATE ABOUT THE IMPLEMENTATION OF HOMESCHOOLING}

\section{RESUMO}

Quando se levanta a temática do homeschooling, em muito se debate sobre a qualidade, eficácia e metodologia do ensino doméstico frente ao escolar. Do mesmo modo, de imediato se confronta a autonomia e responsabilidade parental diante do melhor interesse, proteção integral e demais princípios infanto-juvenis. Não obstante esses desafios, certo é que o ensino doméstico é algo que transcende a esfera individual de pais e jovens e diz respeito também sobre a relevância de estar em sociedade, conviver com a mesma e estabelecer relações. Falar de direito à sociabilidade infanto-juvenil é buscar a compreensão de que para se fazer a parte, pode ser mister a relevância e influência do todo nessa construção. A metodologia utilizada consiste na revisão bibliográfica de teses e artigos científicos sob o viés da abordagem indutiva.

Palavras-chave: Homeschooling. Sociabilidade. Autonomia Parental. Crianças. Adolescentes.

\section{ABSTRACT}

When the theme of homeschooling is raised, there is much debate about the quality, effectiveness and methodology of homeschooling in relation to schooling. Likewise, parental autonomy and responsibility are immediately confronted in the face of the best interest, full protection and other child-juvenile principles. Despite these challenges, it is certain that homeschooling is something that transcends the individual sphere of parents and children but also concerns the importance of being in society, living with it and establishing relationships. Talking about the right to child-juvenile sociability is to seek the understanding that, in order to play a part, the relevance and influence of the whole in this construction may be necessary. The methodology used consists of a literature review of theses and scientific articles under the inductive approach.

Keywords: Homeschooling. Sociability. Parental Autonomy. Kids. Teenagers.

\section{INTRODUÇÃO}

Apesar de estar-se-á vivendo um Estado Democrático de Direito, fruto de muitas lutas e dentre elas não só o reconhecimento de direitos fundamentais dentro de uma faceta axiológica, mas também o (re)conhecer de novos sujeitos enquanto detentores de garantias e legitimadores de uma proteção especial, ainda é fácil se deparar com o desrespeito e condutas que acabam por gerar violações nas esferas desses indivíduos. De novos sujeitos, em verdade, nada possuem, mas apenas recentemente e mediante uma construção e busca material pela concretização de direitos humanos, é que se pode atentar que além de destinatários de direitos, são detentores de uma atenção

\footnotetext{
${ }^{1}$ Mestranda em Direito pela Unichristus. Bolsista PROSUP/CAPES. Especialista em Direito da Família, Infância e Juventude (UNDB). Especialista em Direito do Consumidor (CEUMA). Advogada. Mediadora e conciliadora pelo Tribunal de Justiça do Maranhão.
} 
específica em virtude de suas particularidades.

Crianças e adolescentes fazem parte desses grupos minoritários que mesmo com um arcabouço legislativo em prol de seu cuidado e políticas públicas direcionadas, por vezes, verificam a utilização errônea de princípios como o do melhor interesse e proteção integral. Não que a família não possa ponderar de acordo com o que acha mais conveniente, mas o que se tem observado é uma interferência parental que prejudica uma cadeia de garantias fundamentais e que colocam por prejudicados o crescimento e desenvolvimento infanto-juvenil.

A temática do homeshcooling ou do ensino domiciliar, vem ganhando força nos últimos anos e se baseia em tendências liberais, não intervencionistas e que colocam a família como centro de direção da vida de crianças e adolescentes. Há quem entenda que esse processo educacional é mais seguro e mais razoável quando ofertado e realizado dentro dos lares e mediante o gerenciar dos próprios pais ou de professores contratados. Não que isto nunca tenha ocorrido e não se tenham casos de sucesso no tocante à formação acadêmica ou profissional desse estudante, mas o que se questiona seria o que para além da educação em espaço escolar, também se perde ou se torna frágil nesse transpor da escola para as casas.

Nesse passo é que se entende que a esfera do desenvolver humano transcende necessidades básicas, engloba uma vertente na qual estar em sociedade e participar da mesma, faz parte desse amadurecimento pessoal. É nela que se monta toda uma estrutura biopsicossocial de enfrentamento, de posturas, de formação de senso crítico, de viabilização de cidadania e de usufruto de garantias. Hoje, talvez seja até possível entender que a sociabilidade é peça integrante desse quebra-cabeça em busca da dignidade da pessoa humana, não há que se falar de eficácia de direitos fundamentais, de relações interpessoais e de concretizações de políticas públicas se o "outro" e sua influência, não forem levadas em consideração.

É exatamente nesse sentido que se percebe que o homeschooling para além de provocar infiltrações de interesses alheios aos das crianças e adolescentes, pode acabar por comprometer a inserção infanto-juvenil na sociedade. Os riscos não se concentram apenas no não estudar conjuntamente com demais estudantes, mas diz respeito à forma dessas crianças e adolescentes de ver, entender, sentir e compreender o mundo. O saber lidar com o diferente, perceber desigualdades sociais, ter estímulos de criatividade e ambientes plurais de convivência, faz com que aquele jovem consiga para além do estar em sociedade, possa criar identificação, pertencimento e caráter cívico.

A implementação do homeschooling é um debate que demonstra como tudo está interligado quando se trata de garantir direitos e concretizar materialmente tais conquistas. Colocar a autonomia parental e demais preferências à frente da esfera de proteção desses sujeitos, é prejudicar para além do direito à educação, toda uma geração de crianças e adolescentes que 
precisa da sociabilidade para se colocar diante do mundo.

Metodologicamente, é interesse analisar de forma indutiva como tais aspectos são de forma isolada e como tratar de homeschooling e o direito à sociabilidade repercute diretamente em garantias fundamentais de crianças e adolescentes. A pesquisa ainda se faz de forma bibliográfica com a leitura e investigação a partir da revisão de teses, dissertações e artigos para compor a reflexão teórica (FINCATO, 2014).

\section{O ENSINO DOMÉSTICO}

É bem comum perceber discussões envolvendo os âmbitos público e privado da vida em sociedade, a ingerência de um em outro, limites, eventuais responsabilizações e o que autorizaria a prevalência ${ }^{2}$ em certo caso concreto. Apesar de ser notório que nenhum direito fundamental é absoluto, certo é que debates como esse acabam por colocar em evidência pontos muito importantes que dizem respeito à concretização de outros núcleos fundamentais, não totalmente expressos, mas que de maneira sistemática e axiológica, fazem parte da busca pela dignidade da pessoa humana.

O homeschooling ou ensino doméstico é um desses entraves que de um lado tem-se a autonomia parental versus a ingerência estatal no sentido de defender os direitos de crianças e adolescentes. Não que dentro dessa suposta autonomia não haja o querer da concretização dessas garantias, mas o que se coloca em campo é até que ponto o direito à educação ficaria prejudicado e se existiriam outros reflexos para além os de formação, no qual o homeschooling viria a prejudicar. A linha parece ser muito tênue tendo em vista principalmente que tratar-se-á de indivíduos em desenvolvimento, e exatamente por esse fator, é preciso levar em conta também o contexto no qual estes estão inseridos.

O ensino doméstico é um movimento muito forte nos Estados Unidos e outros países de origem anglo-saxônica, e que vem ganhando espaço ao redor do mundo. Consiste não na inexistência, repulsa ou abolição do ensino nas escolas e universidades, mas no entendimento no qual a educação se faz dentro de uma perspectiva ampla, reduzi-la ao espaço escolar seria restringir o processo de aprendizagem. Nesse mesmo sentido, o ambiente doméstico se faria também um possível auxiliar nessa construção de conhecimento, bem como seria mediante na presença dos pais ou de profissional especializado que o jovem teria aulas e realizaria exercícios de fixação (CURY, 2017).

Seria uma espécie de quebra com uma ideia de Estado intervencionista visto que se refuta

\footnotetext{
2 "Levando-se em consideração o caso concreto, o estabelecimento de relações de precedências condicionadas consiste na fixação de condições sob as quais um princípio tem precedência em face do outro" (ALEXY, 2012, p. 96).
} 
a obrigatoriedade e indicação do ensino ocorrer em ambientes escolares. O dever de educar e a legitimidade para tanto não deveria se concentrar nas mãos estatais, ainda que se permita o ensino nas instituiçõoes privadas. Frisa-se assim, uma atuação liberal do Estado na flexibilização e autorização para que o ensino ocorra tanto nos lares como mediante a observação parental. Há tanto a quebra de uma imposição espacial para a ocorrência o binômio ensino-aprendizagem nas casas, como também se pede pelo reconhecimento da educação enquanto um dever de responsabilidade solidária, na qual a família, enquanto membro de uma rede de apoio tríade para com crianças e adolescentes, possa vir a praticar e auxiliar nas metodologias de estudos (CURY, 2017).

Essa tendência liberal também guarda consigo nuances jusnaturalistas britânicas na qual se coloca que os pais é que são detentores da escolha sobre qual educação querem que seus filhos sejam submetidos. Detentores não em um sentido totalitário e impositivo, mas que por conhecerem suas crianças e seus adolescentes, seriam mais capazes de guiá-los nesse caminho. Atrelado a esta vertente, os responsáveis desses jovens seriam os "melhores representantes de seus interesses" haja vista o sentimento e elo envolvido dentro das famílias (COSTA, 2015).

A intervenção estatal neste caso, romperia o desenvolvimento infanto-juvenil haja vista que quem faz parte do ambiente tradicional de educação não teria proximidade e conhecimento suficientes sobre todos os alunos e de modo a entender qual método e qual conteúdo seria melhor a ser ministrado (COSTA, 2015).

Defendem ainda que atualmente, com a proliferação e democratização de cursos online, materiais pedagógicos e recursos tecnológicos, seria possível realizar essa captação de conhecimento na mesma qualidade que as instituições ordinárias de ensino. Não haveria portanto, argumento afirmando que determinado aluno não iria possuir o material adequado haja vista não frequentar a escola. Dentro de seu próprio lar haveria acesso a livros, vídeos, podcasts, testes e demais instrumentos que contribuíssem nessa didática (BARBOSA; OLIVEIRA, 2017).

Com as tecnologias e a internet, uma nova lógica passa a definir as possibilidades de aprendizagem, uma vez que esta passa a ser possível mediante o uso de plataformas online, ambientes virtuais e aplicativos diversos. Nesse caminho o pai assinou um curso online, Descomplica19, que trabalha com aulas prévestibulares, reforço escolar, dentre outras coisas. Além disso, foram utilizados vários vídeos gratuitos disponíveis no YouTube, o que possibilitou ao educando estudar por meio do computador ou celular, mesmo durante as viagens que a família realizava, isto é, adaptando os estudos à própria dinâmica familiar (PESSOA, 2019, p. 89)

Tendo em vista a questionável eficácia da oferta educacional pelo Estado, este não deveria tecer todos os direcionamentos de quem, onde e como deveria educar ou ser educado (CELETI, 2011). Claro que falar de qualidade educacional sob o viés americano, é bem diferente do 


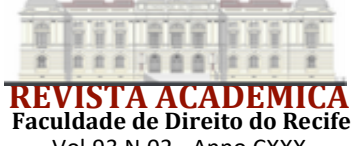

Voldade de Direito do Recife

Vol.93 N.02 - Anno CXXX

brasileiro, pois estar-se-á tratando de países com índices de desenvolvimento diferentes. No caso do Brasil, a discussão nesse aspecto ganharia força tendo em vista o ínfimo investimento na educação de jovens, formação de professores, incentivo à pesquisa, à extensão, carência de livros didáticos, recursos áudio visuais, de prédios bem equipados e acesso à uma merenda escolar satisfatória.

Colocar este debate à tona, não só abarca inicialmente a questão educacional do público infanto-juvenil, como também acaba demonstrando de maneira direta ou reflexa que existe uma certa padronização do perfil de famílias que preferem adotar a educação doméstica. Tal caracterização para além de enquadrar os sujeitos envolvidos, deixa evidente que não é toda família que possui poder aquisitivo, acesso a tecnologias e materiais adequados para o homeschooling. No mesmo passo, a constituição familiar desse contexto acaba por demonstrar que ainda se faz muito forte a ingerência de valores morais, religiosos, políticos e culturais nessa retirada da ingerência estatal e preferência pela autoridade parental.

No Brasil, consistem em famílias dispostas entre as classes média e média alta, dentro de uma formação heterossexual, na faixa de dois a três filhos, ambos os pais cursado o ensino superior e que preservam os valores cristãos (PESSOA, 2019). Paralelo a isto, soma-se o fato de que são famílias que conseguem criar rotinas de estudos em casa, acompanham os filhos e conseguem essa dedicação mais próxima. Realidade esta bem sabida, que não configura grande parte da sociedade brasileira na qual muitos pais e mães precisam deixar seus filhos em casa, na residência de vizinhos, creches ou mesmo nas escolas, para irem trabalhar (GAVIÃO, 2017).

Não se trata de não quererem ajuda, mas uma pergunta que poderia ser levantada é justamente quem são os pais que podem implementar ou auxiliar no ensino doméstico? A resposta pelo visto, não está na base da pirâmide social, mas no topo dessa.

Quanto à relevância da tutela religiosa frente ao ensino doméstico, cada vez mais valores desta linha se tornam justificativas para que haja a prevalência da autonomia parental em nome dos supostos interesse de crianças e adolescentes. Até a discussão sobre a hesitação vacinal desse público por parte de seus responsáveis, possui nos âmbitos religiosos, culturais e políticos pressupostos para a não vacinação. Neste caso, existe ainda toda uma preocupação de possíveis efeitos adversos mesclados com a defesa de fake news que acabam por comprometer todo um sistema de imunização (SUCCI, 2018).

Não são apenas os interesses parentais que estão em jogo, mas garantias que extrapolam a esfera individual. No caso do ensino doméstico, concepções do âmbito moral revestem a defesa desse tipo de educação na qual a obrigatoriedade do ensino nas escolas e supostos riscos que essas crianças estão submetidas nesse espaço, incorporam tal posição. 
Ou seja, dentre os principais motivos das famílias [ ...] destacamos os seguintes: a- preocupação com o ambiente das escolas regulares, algo que inclui segurança, drogas ou pressão do grupo; b- oferecer instrução religiosa ou moral aos seus filhos; c-insatisfação com a instrução das escolas regulares; d- necessidades especiais dos filhos; e- outras razões, tais como, a distância, finanças e a necessidade de um ensino e individualizado (COSTA, 2015, p. 91)

O ambiente escolar antes tão valorizado, passa a ser fonte de desconfiança em um mundo no qual os lugares nos quais crianças e adolescentes deveriam estar mais protegidos, podem oferecer tantos riscos quanto fora das salas de aula. $\mathrm{E}$ os riscos aqui levantados pela preferência do homeschooling dizem respeito não apenas aos físicos, mas também aos sexuais, morais ou de cunho psicológico. Entre a exposição e a proteção, muitos pais preferem preservá-los na garantia não só de suas integridades como no tocante a continuidade do processo educacional.

Ao que parece, se levar em consideração que para o crescimento e desenvolvimento saudável de uma criança e de um adolescente, hoje, existe uma série de garantias que devem ser acopladas para a devida proteção, levantar o debate sobre o ensino doméstico perpassa toda uma construção que vai além do ensino, da aprendizagem, dos muros das salas de aulas ou dos ambientes dos lares.

Os sujeitos envolvidos não são apenas professores, alunos, coordenação pedagógica e os pais, é algo muito maior tendo em vista as próprias conexões que o mundo contemporâneo coloca e pede. Afastar o público infanto juvenil das escolas por conta de defesas baseadas na autoridade parental e algumas ideologias, pode prejudicar algo que diz respeito à própria identificação, referência e inclusão dessas crianças e adolescentes na sociedade.

\section{DIREITO À SOCIABILIDADE}

Em muitos momentos da história humana, o interagir, estabelecer relações, dialogar, comunicar e compartilhar de interesses e posições, foram ações necessárias para a própria sobrevivência. Quando se diz que o homem é um ser social, talvez seja possível colocar que essa tendência à coletividade não se faz apenas em situações de escassez ou de conveniência física, mas engloba também esferas morais, sentimentais, de saúde, psicológicas, de cidadania, profissionais e até de vizinhança. Relações, mesmo as mais esporádicas e pontuais, de alguma forma podem dizer respeito a construções que transcendem valores individuais e colaboram em certa medida para a identificação, crescimento e desenvolvimento humano na sociedade (RIBEIRO, 2010).

A figura da sociabilidade ou da socialização, consiste em uma tendência humana à 
sociedade, ao viver, interagir e se inserir nessa. Pode-se dizer que seria um meio no qual o homem teria para o desenvolver de habilidades e competências, é nela que se esgota ou que se tenta esgotar aptidões necessárias para a sobrevivência. É nesse espaço que se busca o aprimorar individual em face do coletivo uma vez que se lida e se pode estabelecer algumas questões de ordem para um consenso entre permissões e proibições. Falar em sociabilidade faz menção à tendência social como reflexo da natureza e por conseguinte, da razão humana ${ }^{3}$ (KALSING, 2012).

Fora percebido que cada vez mais o estar em sociedade e vivenciá-la, qualificava o homem dentro da sua individualidade. Ser social não significa abolir características intrínsecas, mas atribui outras razões de ser e estar desse sujeito perante os demais. É bem possível que se não houvesse essa interação e determinado individuo se percebesse enquanto totalmente isolado de qualquer convívio, muitas de suas capacidades estariam prejudicadas haja vista o precisar do outro.

Importante frisar que a noção de Estado e sua formação coletiva não se faz enquanto base dessa tendência social. Não há que se dizer que apenas dentro de uma formação estatal é que se pode falar em sociabilidade e no exercício dessa, pelo contrário, os sujeitos antes mesmo de estarem em conjunto em uma delimitação territorial, já possuem essa pré-disposição e já podem estabelecer relações mesmo que não reconhecidas por autoridades ou não estarem dentro de uma circunscrição oficial (HANSEN, 2019).

Isso porque, se uma das dimensões do Estado de Direito implica na compatibilização da vida coletiva para a coexistência das liberdades, por conseguinte essas liberdades plúrimas e suas manifestações se apresentam como anteriores logicamente ao próprio Estado de Direito, por expressarem o acontecer humano no mundo, enquanto interrelacional (HANSEN, 2019, p. 31-32)

Antes do homem ser "alguém" no sentido coletivo, ele se faz enquanto individuo com vontades, desejos e opiniões. Essa situação anterior levanta que para a sociabilidade existir e ser aprimorada, é mister que o sujeito seja livre. Liberdade nas mais diversas esferas, campos de escolhas e de atuação. A liberdade não tem necessariamente conexão com a existência de amarras, mas sim com uma emancipação de espírito, de existência e de condições plausíveis para o desenvolvimento digno da condição humana. ${ }^{4}$

Não há na Constituição Federal de 1988 uma norma expressa falando sobre a sociabilidade

3 "Os jusnaturalistas estabelecem portanto um corte entre a sociedade civil, a civitas, e a sociabilidade natural dos homens, corte esse possibilitado pela intervenção deliberada da razão" (OLIVEIRA, 2000, p. ?)

${ }^{4}$ O Estado precisa e deve oferecer condições para que essas liberdades ocorram e possam continuar sendo aprimoradas, é dentro da criação de oportunidades que essas aptidões transcendem reflexos locais e ganham dimensões gerais. Expandir liberdades é "o fim prioritário e, simultaneamente, o meio principal do desenvolvimento". Não há que se falar em Estado desenvolvido se quem o compõe não possui a autonomia e independência necessárias para a construção e usufruto de garantias fundamentais (SEN, 2018). 
e sua importância, entretanto levando em consideração nuances neoconstitucionalistas, proteção da dignidade da pessoa humana e a constitucionalização de algumas searas do Direito, em especial a do Direito Civil, pode-se dizer que o direito à sociabilidade seria uma construção axiológica na qual se prima pela garantia de um individuo não só de desfrutar do estar em sociedade, mas de poder crescer e se desenvolver diante do meio.

É criar condições e oportunidades para que as liberdades possam ser exercidas e em alguma medida, que essas interações, relações e conexões possam acrescentar na construção individual, fazer valer processos comunicacionais, permitir contatos de cunho econômico, político, educacional, cultural, social e profissional, por exemplo. Direito à sociabilidade ou a socialização, é facilitar e proporcionalizar formas de identificação, de encaixes, de espelhos.

A socialização assume, assim, essencialmente, duas funções: é um meio de tecer relações com os outros e de se integrar em grupos e/ou instituições, de modo a assimilar, paulatinamente, as normas os valores e os códigos sociais que permitirão ao indivíduo de se conformar com as exigências sociais; e, paralelamente, irá permitir a afirmação da individualidade de cada um, bem como um lugar específico na sociedade [...] É graças aos outros que nos tornamos nós mesmos e que aprendemos a conhecermo-nos, visto que o outro tem o papel de uma espécie de espelho (RIBEIRO, 2010, p. 34-35).

Na nova leitura civilista brasileira, a sociabilidade está presente em novos princípios como o da função social da família e da afetividade. É por meio dessas conexões que tanto se atribui um papel relevante no cuidado, zelo e desenvolvimento de crianças e adolescentes para além da esfera privada, é no cerne dessas relações que podem nascer ou ser identificados parâmetros de uma paternidade socioafetiva, por exemplo.

A influência externa para com o indivíduo na contemporaneidade, demonstra que cada vez e de maneira mais rápida, são perceptíveis mudanças nas dinâmicas sociais cujo acompanhar precisa ser realizado para além de atividade regulatória. Trata-se do legitimar, proteger e compreender a multiplicidade própria do ser humano, e fazer desta, uma bandeira dentro dos escopos do Estado Democrático de Direito (TARTUCE, 2008).

Falar nessa garantia implica um liame necessário para o estabelecer de relações verticais e horizontais dentro da eficácia de direitos. É a partir da sociabilidade que se verifica, se organiza e se podem reger os contatos necessários para a convivência em sociedade e seus desdobramentos. Em algum momento os indivíduos são emissores, receptores, são promovedores ou destinatários nas relações interpessoais, até para se falar na preponderância de um direito sobre outro, se pressupõe que em algum momento ocorrera uma interação para que houvesse certo confronto de garantias (FERNANDES, 2012). 
Nesse sentido de trânsito de posições e o dialogar de direitos fundamentais, é que se tem a cidadania como outro campo no qual a sociabilidade serve como um dos basilares primordiais. É nela que se podem estimular participações, atuações mais ativas que passivas e processos de identificação sócio culturais. É por meio do coletivo que se pode tornar viável a comunicação de necessidades, o empenho na redução e enfretamento de desigualdades sociais e a busca por uma democracia muito mais qualitativa do que somente quantitativa (HANSEN, 2019).

Estar em sociedade não implica apenas em uma convivência por si só, todo o contato que se pratica é capaz de impactar a esfera subjetiva do individuo tanto de forma direta quanto indireta. A questão da sociabilidade perpassa exiguidades tanto de cunho físico, como mental, moral, cultural, psicológico, profissional, político, econômico ou social, e atribuir esta garantia enquanto uma esfera de proteção humana, é compreender não só a conexão intrínseca do vivenciar coletivo, como também o legitimar das ações e reações que uns possuem diante da vida dos outros.

Direito à sociabilidade ou à socialização é algo que nasce no bojo particular e repercute esferas à diante. É saber que pode até ocorrer sim um crescimento e um desenvolvimento humano de forma isolada ou sem qualquer interação, mas certamente essa carência do outro vai impactar fortemente no crescer e desenvolver qualitativo desse sujeito. Se coloca a sociabilidade não como necessidade de companhia, mas como urgente o reconhecimento de que é no meio que pessoas se formam, se reconhecem, se identificam e podem se colocar enquanto agentes de mudanças na sociedade hodierna.

\section{SOCIABILIDADE INFANTO-JUVENIL E O HOMESCHOOLING}

Falar sobre implementação do homeschooling desperta diversos outros debates dentro e fora do âmbito educacional, não só em virtude da reformulação sobre o que seriam espaços educacionais, mas principalmente em virtude dos sujeitos que podem mais ser impactados nesse deslocamento: crianças e adolescentes. A mudança para o ensino doméstico pode de fato, reduzir custos, distâncias, tentar ter certa adaptação no tocante ao conteúdo e eliminar certos "riscos" apontados pelos pais, todavia alguns pontos devem ser analisados não por meio da autonomia parental versus o papel do Estado no ensino formal, mas tratar-se-á da relevância do estar no ambiente escolar em detrimento da sociabilidade infanto-juvenil.

Bem sabido é que a família corresponde à primeira instituição ${ }^{5}$ socializadora de uma

\footnotetext{
5 Vale lembrar que no seio familiar crianças e adolescentes, por vezes, são notadas apenas dentro de suas particularidades intrínsecas, quais sejam, as ligadas à condição especial de desenvolvimento. Todavia, é certo que para garantir efetivamente os direitos infanto-juvenis frente às mais diversas formas de violência e discriminação, se faz mister considerar as vulnerabilidades extrínsecas, aquelas ligadas ao meio, ao contexto no qual esses jovens
} 
criança logo no início e decorrer da vida, é ali que ela possui contato com as primeiras referências de comportamento, valores e exemplos. Acoplam-se durante seu crescimento as opções morais e culturais presentes naquele seio familiar, de modo que com o passar do tempo e com o inicio de um contato com o mundo externo, é que se poderá não só conhecer outras realidades como sentir, olhar, escutar e formar senso crítico mediante o encontro com o diferente. Em momento algum se quer retirar esse papel tão fundamental da família nesse primeiro cuidado do ser humano em meio ao mundo, mas o que se atenta é que apesar da configuração familiar ser um agente de sociabilidade, ela não é e talvez não deva ser a única ${ }^{6}$ (PICOLI, 2020).

Concentrar a troca e contato de experiências, valores, posições e visões de mundo apenas na esfera privada compromete a sociabilidade infanto-juvenil visto que se direciona aquele jovem para ensinamentos que devam prevalecer e tidos como corretos. É no ambiente escolar que se pode falar em "trocas culturais" e estas vão além de conteúdos e atividades ministradas, diz respeito ao contato e à interação do demais colegas, professores e funcionários. Enquanto o ensino doméstico prima pela unidade, é na educação realizada em ambiente escolar que se tem a pluralidade necessária para auxilio de um desenvolvimento mais inclusivo, tolerante e múltiplo (CARVALHO RIBEIRO, 2020).

Esse tipo de socialização compreende uma extensão da socialização primária que, embora demasiadamente importante, compreende uma forma de socialização entre os iguais. Não está, portanto, aberta para o outro, e, consequentemente, não ajuda na transição entre a esfera privada e a esfera pública. [...] Em sociedade marcadas pela diversidade étnico-racial e religiosa, como é o caso da brasileira, a Educação escolar exerce um papel significativo e, mesmo, insubstituível, na apresentação do mundo (PICOLI, 2020, p. 12)

Exatamente por conta da necessidade dessa pluralidade, que adotar o homeschooling vai de encontro com o preceito do art. 205 da Constituição Federal haja vista que o pleno desenvolvimento da pessoa, seu preparo para a cidadania e sua qualificação para o trabalho, se dão de maneira qualitativa e significativa dentro da sociedade. Formação intelectual não é algo restrito à escola em si, mas a formação subjetiva se dá mediante análises, opiniões, críticas e

estão inseridos. Esse olhar "de fora", esse olhar "do outro", em muitas situações é feito por instâncias socializadoras diferentes das familiares, são escolas, são igrejas, são pais de outros colegas, professores de atividades físicas, creches e conselhos tutelares que de algum modo captam sinais que nem sempre são considerados portas à dentro (SANTOS; VERONESE, 2018).

${ }^{6}$ Ao mesmo passo que se coloca a família enquanto primeiro contato para com o meio social e que em tese, nela é que estaria o maior e melhor âmbito de proteção para com crianças e adolescentes, é bem sabido que em muitos casos é no seio familiar que ocorrem diversas violências, situações de discriminação, maus tratos, e geralmente, tais atos são praticados pelos próprios familiares. Entender que apenas dentro do âmbito privado é que se pode falar de segurança e distância de riscos em detrimento do restante do mundo, é realmente desconhecer que a vulnerabilidade desses jovens por vezes está justamente no local no qual deveriam estar mais protegidos e assistidos (PICOLI, 2020). 
compartilhamento, e isto apenas dentro do meio e das dinâmicas interrelacionais é que se pode ter acesso (SILVA; ALMEIDA, 2019).

\begin{abstract}
Atualmente, a escola mantém a função de promover a integração social como uma das suas finalidades. Essa perspectiva reflete uma forma de apreensão da relação que a criança estabelece com a sociedade e com as diferentes instâncias socializadoras. Predomina, nessa concepção, a centralidade da escola na mediação da relação indivíduo e sociedade, direcionando e definindo todos os elementos constitutivos dos processos de socialização (MENDANHA, 2011, p. 49).
\end{abstract}

É na escola que se incentiva um papel mais ativo por parte da criança no tocante ao processo de socialização, para além da captação informativa, se estimulam brincadeiras, jogos interações, visitas a campo, contato com outras turmas, atividades que requerem raciocínio lógico e feiras culturais. São encontros que o ensino doméstico não é capaz de proporcionar de maneira absoluta, aqui pelo contrário, o jovem é mais um mero expectador, um sujeito passivo nessa construção de conhecimento (CORSARO, 2011).

O fato de estarem em condição especial de desenvolvimento, não os torna incapazes de tomarem atitudes dinâmicas, de proporem assuntos com os quais possuem curiosidade, de realizarem atividades em grupo, de participar de gincanas ou mesmo de dialogar com diversos setores da própria escola, são momentos como esses que se criam condições para uma autonomia infantil e juvenil (SILVA, 2017).

Entre o distanciar e o aproximar do espaço escolar, deve-se ter em mente que a proximidade é mais favorável na edificação de pontes sociais, e que ao fundo, não se trata somente entre imposição estatal para um ensino formal e uma decisão parental sob a luz de um suposto melhor interesse e de uma suposta proteção integral. Crianças e adolescentes são seres sociáveis assim como qualquer humano, mas apesar dessa semelhança, de nada adianta chama-las como tal se é cerceado, ignorado ou não reconhecido seu direito à sociabilidade.

É na sociabilidade extra muros dos lares, e em especial, no ambiente escolar, que esse movimento "para frente" é semeado, crianças e adolescentes são construtores, proponentes e produtores de cultura infantil. E esta acaba sendo um guia para as metodologias pedagógicas, para a forma de comunicação entre professores e alunos, saber como esses estudantes se comportam, o que falam, o que fazem, o que preferem, como se expressam e como se colocam diante de desafios, faz com que o espaço escolar consiga por vezes estar bem mais próximo do que a própria família. Proximidade nesse caso, não se trata necessariamente de encurtamento de distancias físicas, mas de reflexo, de similaridade, de representação e de escuta (SILVA, 2017).

Garantir esse direito é fazer valer não só a responsabilidade tríade da família, Estado e 
sociedade, como também proteger o melhor interesse e a proteção integral diante de uma autonomia parental que coloca em risco muito mais que o direito à educação. Não se perde em conteúdo, se perde na criação de situações e oportunidades de fazer esses estudantes pessoas preparadas para os desafios da vida em sociedade. As violências derivadas da preferência do ensino domiciliar no lugar do escolar podem reverberar gerações em diante.

Os direitos não pertencem a humanos plenamente formados como garantias préexistentes da natureza ou como resultado de algum acordo original ou como expressões da objetividade moral. Ao contrário, os direitos são instrumentos através dos quais as pessoas constroem suas identidades em uma luta constante para o reconhecimento com outras pessoas e do "Grande Outro" das instituições sociais (DOUZINAS, 2014, p.7)

Nesse caso, a implementação do homeschooling acaba por prejudicar toda uma esfera de direitos fundamentais sob a ótica de argumentos que ou se baseiam na suposta autonomia parental ou em muitas ocasiões, estão regidos dentro de fundamentos culturais, religiosos e políticos. Não está se querendo dizer que nenhuma convicção é válida, mas em momento no qual essas valorações comprometem toda uma construção axiológica ou de garantias fundamentais, estes devem preponderar em face do que pais ou responsáveis venham a alegar.

\begin{abstract}
A posição de sujeito de direitos é um processo, e assim como o desenvolvimento de crianças e adolescentes, algo constante e que necessita de atenção. Infelizmente algumas conquistas nas áreas políticas, jurídicas e econômicas não representam avanços sociais, culturais e de reconhecimento de identidade. Ser sujeito de direito na contemporaneidade é lutar contra sistemas hegemônicos antigos e novos, é entender que as necessidades não são universais e muito menos que esses indivíduos podem constituir objetos de entraves de interesses alheios quando são na realidade os verdadeiros protagonistas deste roteiro (FALCÃO, 2020, p. 82).
\end{abstract}

Pode-se dizer que com o direito à sociabilidade infanto-juvenil estar-se-á tratando também do direito desse grupo de estar próximo às mais diversas interações. Próximo às desigualdades, que nem sempre são apresentadas nos lares, próximos das diferenças existentes nas diversas infâncias, visto que nem sempre a condição sócio econômica de uma criança será igual a outra. Não se pode acreditar que o homeschooling conseguirá apresentar a esses alunos todos os percalços e obstáculos inerentes da vida em sociedade, não se pode garantir que o ensino doméstico irá ser satisfatório em matérias básicas e, de outro lado, carente em disciplinas que auxiliam na formação de senso crítico.

Espaços sociais devem ser ocupados, escolas devem ser ocupadas, relações entre alunos, professores, colegas de sala, coordenação, funcionários e tudo aquilo que engloba a educação, deve 
ser e estar próximo a esses estudantes. O desenvolvimento infanto juvenil é algo dinâmico, de movimento, plural e diverso, sendo assim, nada mais coerente do que aceitar que o afastamento para com o ensino domiciliar representa a estagnação de toda uma mobilidade necessária para um viver com dignidade.

\section{CONSIDERAÇÕES FINAIS}

Por mais que diferenciem direitos dentro de dimensões, dentro do âmbito de atuação, de acordo com seus destinatários ou conforme a eficácia, tais garantias estarão sempre conectadas haja vista que para a concretização material de uma, se faz mister a presença de outra. Direitos fundamentais são ao mesmo tempo o caminho e o instrumento nessa tentativa constante de proteção no Estado contemporâneo.

O debate apresentado possui em seu bojo justamente essa conexão e interdependência de garantias fundamentais que, por mais que haja toda uma estrutura direcionada para a sua operacionalização, alguma peça dessa montagem faltará ou estará alocada de maneira errônea se não for levado em consideração o todo. Estar-se-á diante de uma sociedade dinâmica, movimentada pelos seus paradigmas e que ignorar a forma como as interações e relações interpessoais influenciam no desenvolvimento humano, é regredir enquanto formação coletiva.

O homeschooling vem enquanto uma alternativa ao ensino formal e como uma ação não intervencionista em comparação à estatal. Muito se levanta a bandeira de segurança, de uma maior atenção, de um estudo mais direcionado, mas pouco se analisa a educação como um todo, como um processo, como a atuação de diversos agentes e como um mecanismo de transformação social. A autonomia parental não pode preponderar em face dos direitos infanto-juvenis sob pena de quebrar toda uma sistemática que além de reconhecer crianças e adolescentes enquanto sujeitos em condição especial de desenvolvimento, tenta analisar sempre a eficácia dessas garantias diante das vulnerabilidades intrínsecas e extrínsecas desses indivíduos.

Falar em direito à socialidade infanto-juvenil é compreender que para se formar cidadãos, gerações formadoras de opiniões, cientes das fissuras sociais, mais tolerantes e respeitosos para com as pluralidades, é necessário que crianças e adolescentes estejam inseridas no espaço escolar. Ambiente este que não se busca apenas um papel passivo de captação de conteúdo, mas se busca tornar esse jovem um personagem ativo no tocante às descobertas, incentivo a criatividade, diálogo com o corpo pedagógico e conhecedor das realidades sociais no entorno do ambiente de ensino.

De fato, não há como pensar em direito à educação sem colocar a sociabilidade enquanto um alicerce fundamental para um binômio ensino-aprendizagem mais próximo. Muito já se luta 
contra as distâncias nas quais historicamente, o público infanto-juvenil enfrenta. Inviável portanto, se faz criar mais obstáculos para uma ponte para além de necessária, fundamental no tocante à criação de liberdades e oportunidades dignas.

\section{REFERÊNCIAS}

ALEXY, Robert. Teoria dos Direitos Fundamentais. 2. ed. São Paulo: Editora Malheiros, 2012.

BARBOSA, Luciane Muniz Ribeiro; OLIVEIRA, Romualdo Luiz Portela de. Apresentação do Dossiê: Homeschooling e o Direito à Educação. Pro-Posições, Campinas , v. 28, n. 2, p. 15 20, ago. 2017. Disponível em: https://www.scielo.br/scielo.php?pid=S0103-

$73072017000200015 \&$ script=sci_arttext. Acesso em: 27 dez. 2020.

CARVALHO RIBEIRO, Adalberto. Homeschooling e controvérsias: da identidade à pluralidade--o drama da socialização. Revista Práxis Educativa, v. 15, n. 1, 2020. Disponível em: https://revistas2.uepg.br/index.php/praxiseducativa/article/view/14775/209209212974. Acesso em: $31 \mathrm{dez} .2020$.

CELETI, Filipe Rangel. Educação não obrigatória: uma discussão sobre o estado e o mercado. 2011. Disponível em: http://tede.mackenzie.br/jspui/handle/tede/1801. Acesso em: 27 dez. 2020.

CORSARO, William Arnold. Sociologia da infância. Tradução de Lia Gabriele Regius Reis. São Paulo: Artmed, 2011.

COSTA, Fabrício Veiga. Homeschooling no Brasil: constitucionalidade e legalidade do Projeto de Lei 3179/12. Revista de Pesquisa e Educação Jurídica, v. 1, n. 1, p. 86-112, 2015.

Disponível em: https://indexlaw.org/index.php/rpej/article/view/5/pdf. Acesso em: 27 dez. 2020. CURY, Carlos Roberto Jamil. Homeschooling: entre dois jusnaturalismos?. Pro-

Posições, Campinas, v. 28, n. 2, p. 104-121, aug. 2017. Disponível em: https://www.scielo.br/scielo.php?pid=S0103-73072017000200104\&script=sci_arttext. Acesso em: 28 dez. 2020.

DOUZINAS, Costas. Quem são os 'humanos' dos direitos. Projeto Revoluções, 2014. FALCÃO, Letícia Prazeres. Judicialização das demandas de vacinação em crianças e adolescentes: a busca pela efetivação do melhor interesse e proteção integral. Revista de Direito de Família e Sucessão, v. 6, n. 2, p. 74-95, 2020. Disponível em: https://www.indexlaw.org/index.php/direitofamilia/article/view/7165. Acesso em: 03 jan. 2020. FERNANDES, Bernardo Gonçalves. Curso de Direito Constitucional. 4. ed. Salvador: Editora JusPodvim, 2012.

FINCATO, Denise Pires. A pesquisa jurídica sem mistérios: da pesquisa à banca. 2. ed. Porto Alegre: Sapiens, 2014.

GAVIÃO, Juliane Soares F. As crianças e suas memórias de infância: escola e homeschooling nas narrativas infantis. 2017. 159 f. Tese (Doutorado em Educação) - Universidade do Rio Grande do Sul, Porto Alegre, 2017.

HANSEN, Gilvan Luiz. Democracia e cidadania como condições de possibilidade da sociabilidade e do estado de direito. Derecho y Sostenibilidad en escenarios de crisis institucionales, p. 29. Disponível em: http://sidecied.com/wpcontent/uploads/2019/11/Conferencias-Magistrales-I-SIDECIED-4.pdf\#page=30. Acesso em: 29 dez. 2020. 
KALSING, Rejane Margarete Schaefer. Sociabilidade legal: uma ligação entre sociabilidade e direito em Kant. 2012. Disponível em:

https://repositorio.ufsc.br/bitstream/handle/123456789/94744/289542.pdf?sequence=1\&isAllowe d=y. Acesso em: 29 dez. 2020.

MENDANHA, Sílvia do Socorro. A socialização escolar na concepção de professores da rede municipal de ensino de Goiânia-GO. 2011. Disponível em:

https://repositorio.bc.ufg.br/tede/handle/tde/2022. Acesso em: 02 jan. 2021.

OLIVEIRA, Isabel de Assis Ribeiro de. Sociabilidade e direito no liberalismo nascente. Lua

Nova: Revista de Cultura e Política, n. 50, p. 159-183, 2000. Disponível em:

https://www.scielo.br/scielo.php?pid=S0102-64452000000200009\&script=sci_arttext. Acesso em: 28 dez. 2020.

PESSOA, Alexsandro Vieira. Práticas pedagógicas na educação domiciliar: um estudo de caso em Aracaju, 2019. Disponível em:

https://ri.ufs.br/bitstream/riufs/11925/2/ALEXSANDRO_VIEIRA_PESSOA.pdf. Acesso em: 26 dez. 2020.

PICOLI, Bruno Antonio. Homeschooling e os irrenunciáveis perigos da educação: reflexos sobre as possibilidades de educação sem escola no mundo plural a partir de Arendt, biesta e Savater.

Revista Práxis Educativa, v.15, n.1, 2020. Disponível em:

https://revistas2.uepg.br/index.php/praxiseducativa/issue/view/694. Acesso em: 30 dez. 2020

RIBEIRO, Célia Carlota Rodrigues Pereira Marques. Relações de sociabilidade, entre

adolescentes, em contexto escolar. 2010. Tese (Doutorado) - Escola Superior de Educação de Paula Frassinetti, Porto, 2010. Disponível em:

http://repositorio.esepf.pt/bitstream/20.500.11796/742/4/TM-ESEPF_2010CeliaRibeiro.pdf.

Acesso em: 27 dez. 2020.

SANTOS, Danielle Maria Espezim dos; VERONESE, Josiane Rose Petry. A proteção integral e o enfrentamento de vulnerabilidades infanto adolescentes. Revista de Direito, Viçosa, v. 10, n. 2, p. 109-157, 2018. Disponível em: https://dialnet.unirioja.es/servlet/articulo?codigo=7085867. Acesso em: 29 dez. 2020.

SEN, Amartya. Desenvolvimento como liberdade. São Paulo: Editora Companhia das letras, 2018

SILVA, Clemildo Anacleto da; ALMEIDA, Emanoel Rodrigues; FERRO, Karla Érika Ferreira. Homeschooling e a negação do direito à educação: um desdobramento do estado

neoliberal. Ciência em Movimento, v. 21, n. 42, p. 103-113. Disponível em:

https://www.metodista.br/revistas/revistas-ipa/index.php/EDH/article/view/899/782. Acesso em: 31 dez. 2020.

SILVA, Elisvânia Amaro da. Entre discursos e práticas: representações sociais de professores sobre a socialização na Educação Infantil. 2017. Disponível em:

https://repositorio.unb.br/bitstream/10482/23997/1/2017_Elisv\%c3\%a2niaAmarodaSilva.pdf.

Acesso em: 02 jan. 2021.

SUCCI, Regina Célia de Menezes. Recusa vacinal-que é preciso saber. Jornal de Pediatria, v.

94, n. 6, p. 574-581, 2018. Disponível em: https://www.scielo.br/scielo.php?pid=S0021-

75572018000600574\&script=sci_arttext\&tlng=pt. Acesso em: 28 dez. 2020.

TARTUCE, Flávio. Novos princípios do direito de família brasileiro. Jus Navigandi, Teresina, v. 10, 2008. Disponível em:

https://ss19183.websiteseguro.com/slap/tiara/artigos/upload/artigos/princfam.pdf. Acesso em: 29 dez. 2020. 